\title{
Towards Achieving Mortality Free Pancreaticoduodenectomy
}

\author{
Amer Qais Ibrahim Aldouri* \\ Department of Consultant Pancreatico-Biliary and General Surgeon, University of Leeds, UK
}

Submission: February 09, 2017; Published: February 20, 2017

*Corresponding author: Amer Qais Ibrahim Aldouri, Department of Consultant Pancreatico-Biliary and General Surgeon, University of Leeds, St. James University Hospital, Beckett’ St., Leeds LS9 7TF, UK, Email: amer2003@gmail.com

Abbreviations: PD: Pancreaticoduodenectomy; SAD: Sagittal Abdominal Diameter; PDAC: Pancreatic Duct Adeno-Carcinoma

\section{Introduction}

In March 1940 Dr. Whipple performed the first one-stage pancreaticoduodenectomy (PD) [1]. This has been adopted as the standard procedure for treating resectable pancreatic head tumors. Although the 90-day mortality post-PD has improved over the last 20 years [2], recent reports from the United State and Germany confirmed that 90-day mortality still higher than $7 \%[3,4]$. In Japan nationwide in-hospital mortality of $2.8 \%$ post-PD has been reported [5]. Authors reported a limited series of mortality free PD in the literature [6-8]. However, it's proved hard to replicate this result even at centers of excellence [9].

Many risk factors have been linked to both 30-day and 90-day mortality following major pancreatic resections [3-5]. Modifying some of these factors led to the reduction in post-PD mortality, for instance the evidence-based hospital referral recommendations in the United State [2]. Further understanding of the modifiable risk factors may contribute to further reduction in post-PD mortality in the near future. In this short report the outcomes of all PD, performed by single surgeon, and are reported with emphasis on the modifiable factors that previously linked to 90 day mortality.

\section{Methods}

\section{Patients}

From May 2011 to August 2016, a total of eighty-three consecutive PD performed by the author. One case extended to total pancreatectomy. All clinical, surgical and laboratory results are retrieved from our database.

The in-hospital mortality was defined as all deaths within 90 days after surgery. Pancreatic fistula was classified according to the International Study Group on Pancreatic Fistula definition and the International Study Group of Pancreatic Surgery classification.

Central obesity defined as high visceral fat area estimated by measuring the sagittal abdominal diameter. Previous studies have demonstrated the value of sagittal abdominal diameter (SAD) both as a reliable predictor of visceral fat mass [10], and better indicator of abdominal operative complexity compared to BMI [11]. Therefore, this method was used to radiologically categorize all patients in this study into either low (SAD $\leq 240$ $\mathrm{mm}$ ) or high visceral fat (SAD $>240 \mathrm{~mm}$ ) groups. The SAD of each patient was determined on axial CT by measuring the midline anterior-posterior thickness of the abdomen at the level of the fourth lumbar vertebra.

\section{Results}

Table 1: Patient characteristics and principal diagnosis. Central obesity defined as high visceral fat area estimated by measuring the sagittal abdominal diameter.

\begin{tabular}{|c|c|c|}
\hline Variables & Number & $\%$ \\
\hline \multicolumn{3}{|c|}{ Age group } \\
\hline$<50$ & 12 & 15 \\
\hline $50-69$ & 41 & 49 \\
\hline$>69$ & 30 & 36 \\
\hline \multicolumn{3}{|l|}{ Sex } \\
\hline Female & 33 & 40 \\
\hline Male & 50 & 60 \\
\hline \multicolumn{3}{|c|}{ ASA class } \\
\hline Class 1 & 5 & 6 \\
\hline Class 2 & 72 & 87 \\
\hline Class 3 or more & 6 & 7 \\
\hline
\end{tabular}




\section{Open Access Journal of Surgery}

\begin{tabular}{|c|c|c|}
\hline Central obesity* & 31 & 37 \\
\hline \multicolumn{3}{|c|}{ Malignant neoplasm } \\
\hline Pancreatic & 46 & 54 \\
\hline Non pancreatic & 26 & 32 \\
\hline \multicolumn{3}{|c|}{ Benign neoplasm } \\
\hline Pancreatic & 8 & 10 \\
\hline Non pancreatic & 3 & 4 \\
\hline
\end{tabular}

The patients' population had a median age of 66 years, range from 24 to 82 years, and $40 \%(\mathrm{~N}=33)$ were females (Table 1). Histological diagnosis of pancreatic duct adenocarcinoma (PDAC) made in $40 \%(\mathrm{~N}=31)$. Cholangiocarcinoma was the diagnosis in $23 \%(\mathrm{~N}=19)$, duodenal cancer was the diagnosis in $7 \%(\mathrm{~N}=6)$ and ampullary tumors was the diagnosis in $13 \%$ $(\mathrm{N}=11)$. The operative time was longer than 6 hours in $88 \%(\mathrm{~N}=$ 66) of patients. There was need for operative blood transfusion in $17 \%(\mathrm{~N}=14)$ of patients. The postoperative complications and post-operative intervention were detailed in (Tables $2 \& 3$ ). There was no in-hospital mortality.

Table 2: Postoperative complications.

\begin{tabular}{|c|c|c|}
\hline Variables & Number & $\%$ \\
\hline \multicolumn{3}{|c|}{ Operative time } \\
\hline$<6$ hours & 11 & 12 \\
\hline$>6$ hours & 72 & 88 \\
\hline Venous resection & 2 & 2 \\
\hline \multicolumn{3}{|c|}{ Operative blood transfusion } \\
\hline None & 69 & 83 \\
\hline $1-3$ units & 13 & 16 \\
\hline 4- 5 units & 0 & 0 \\
\hline$>5$ units & 1 & 1 \\
\hline \multicolumn{3}{|c|}{ Post-operative complications } \\
\hline DVT or PE & 1 & 1 \\
\hline Pneumonia & 12 & 15 \\
\hline Peritonitis & 1 & 1 \\
\hline Sepsis & 14 & 17 \\
\hline Acute renal Failure* & 0 & 0 \\
\hline \multicolumn{3}{|c|}{ Pancreatic fistula / leak } \\
\hline Grade A & 3 & 4 \\
\hline Grade B & 12 & 16 \\
\hline Grade C & 2 & 2 \\
\hline Bile leak & 2 & 2 \\
\hline \multicolumn{3}{|c|}{ Post-operative interventions } \\
\hline Re-laparotomy & 5 & 6 \\
\hline $\begin{array}{c}\text { Blood transfusion }> \\
5 \text { units }\end{array}$ & 2 & 2 \\
\hline $\begin{array}{c}\text { Mechanical } \\
\text { ventilation }>48 \mathrm{hrs}\end{array}$ & 0 & 0 \\
\hline $\begin{array}{l}\text { Radiological Vascular } \\
\text { intervention }\end{array}$ & 1 & 1 \\
\hline
\end{tabular}

Table 3: Postoperative complications and related mortality rate compared to German nationwide report.

\begin{tabular}{|c|c|c|c|c|}
\hline & $\begin{array}{l}\text { Current } \\
(\mathrm{N}=83)\end{array}$ & Study & $\begin{array}{l}\text { Nimptsch } \\
(\mathrm{N}=31293)\end{array}$ & et al. \\
\hline Variables & $\begin{array}{c}\text { Prevalence } \\
\%\end{array}$ & $\begin{array}{c}\text { Mortality } \\
\%\end{array}$ & $\begin{array}{c}\text { Prevalence } \\
\%\end{array}$ & $\begin{array}{c}\text { Mortality } \\
\%\end{array}$ \\
\hline \multicolumn{5}{|c|}{ Post-operative complications } \\
\hline DVT or PE & 1 & 0 & 1.7 & 21.6 \\
\hline Pneumonia & 15 & 0 & 9.2 & 26 \\
\hline Peritonitis & 1 & 0 & 9.7 & 27.1 \\
\hline Sepsis & 18 & 0 & 9.4 & 37.8 \\
\hline $\begin{array}{l}\text { Acute renal } \\
\text { Failure }\end{array}$ & 0 & 0 & 7 & 52.2 \\
\hline \multicolumn{5}{|c|}{ Post-operative interventions } \\
\hline Re-laparotomy & 6 & 0 & 13 & 28.6 \\
\hline $\begin{array}{c}\text { Total blood } \\
\text { transfusion }>5 \\
\text { units }\end{array}$ & 2 & 0 & 16.7 & 30.2 \\
\hline $\begin{array}{c}\text { Mechanical } \\
\text { ventilation > } \\
48 \mathrm{hrs}\end{array}$ & 0 & 0 & 11 & 41.1 \\
\hline $\begin{array}{l}\text { Radiological } \\
\text { Vascular } \\
\text { intervention }\end{array}$ & 1 & 0 & 1 & 36.3 \\
\hline
\end{tabular}

\section{Discussion}

In-hospital mortality post-PD was linked to both modifiable and unmodifiable risk factors. Preoperative risk factors include age, obesity, ASA class and bleeding disorder [12]. More importantly are the operative and postoperative factors, which can be modified in attempt to reduce the postoperative complications and mortality. The operative factors include blood loss and operative transfusion [5]. The postoperative factors are unplanned ventilation of more than 48 hours, renal failure, septic shock, cardiac complications and central nervous system complications [5]. Preoperative risk factors include age, obesity, and ASA class are unmodifiable risk factors, however it is important to know their prevalence to determine whether patient selection had a major role in achieving the reported outcomes.

Patients aged 70 years or older are at high risk of in-hospital mortality [2]. Nimptsch et al. [4] reported in-hospital mortality of $14.9 \%$. In their report nearly $40 \%$ of the patient underwent pancreatic resection were 70 years or older [4]. In our cohort; $36 \%(\mathrm{~N}=30)$ of patients were 70 years or older, although none of them died during 90 days postoperative period, the risk was there and should be seriously considered during decision making process and the preoperative consultation with the patients, especially in those with premalignant lesions. Obesity is another risk factor [5], Kimura et al. [5] reported that $14.8 \%$ of their patients were overweight or obese, in our cohort $37 \%(\mathrm{~N}=$ 31 ) had central obesity. Seven per cent $(N=6)$ of our patients 
had ASA class of 3 or above, this prevalence is comparable to that reported in the literature [5]. The prevalence of bleeding disorder in our cohort $1 \%$ is slightly lower than that reported by Kimura et al. (3\%) [5]. These findings suggest that our patients' cohort had comparable preoperative risk factors, include age, obesity, ASA class and bleeding disorder to that published in the literature. This support the conclusion that patient's selection was a minor factor in achieving the reported results.

Operative blood transfusion provides an adequate tool for indirectly assessing bleeding during pancreatectomy [4]. Kimura et al. [5] concluded that operative blood transfusion associated with in-hospital mortality, and they reported that transfusion of more than 5 units required in 36\% of PD performed in Japan during 2011. In the current study $1 \%$ of PD required operative blood transfusion of more than 5 units; however 16\% of PD required transfusion of 1-3 units. This difference in the need for operative blood transfusion reflects the difference in the operative blood loss. Many factors influence operative blood loss including presence of bleeding disorder, vascular resection, and the surgical technique. In the current study one patient had bleeding disorder and required postoperative transfusion. The prevalence of bleeding disorder in our cohort (1\%) is slightly lower than that reported by Kimura et al [5] (3\%). Two patients required vascular resection, although vascular resection is a recognized factor associated with increase blood loss, it is not a significant risk factor for in-hospital mortality $[4,13]$.

Operative technique; specifically artery first approach is associated with significant reduction in operative blood loss [10]. Planned navigation around the superior mesenteric vessels directly linked to reduction in operative blood loss the need for blood transfusion, and authors reported zero in-hospital mortality for patient who had this technique [10]. Operative blood loss is a modifiable risk factor that can be reduced by implementing meticulous operative techniques. However, other postoperative events including postoperative blood transfusion, unplanned ventilation, renal failure, and septic shock are influenced by the operative technique too.

Investigation of bariatric surgery has shown that technical skill is a very important contributor to postoperative complications and mortality [11]. Birkmeyer et al. [14] study showed that as compared with patients treated by surgeons with high skill rating, patients treated by surgeons with low skill ratings were at least twice as likely to die. It is likely that PD is no different, although more direct study of this is needed. Studies of PD showed that improvement in operative technique during the learning curve resulted in significant reduction in operative blood loss, and hospital stay. Further investment in developing meticulous operative technique may achieve reduction in postPD mortality by reducing the operative and postoperative risk factors.

In this study the prevalence of grade $\mathrm{A}, \mathrm{B}$, and $\mathrm{C}$ pancreatic leak / fistula was $4 \%, 16 \%$ and $2 \%$ respectively. This higher than what reported by Kimura et al. [5] (grade B and C of 13\%). However, this higher leak rate did not lead to in-hospital death. This could be explained by the fact that Kimura et al. [5] reported only $7 \%$ mortality among patients with pancreatic fistula grade $\mathrm{B}$ or $\mathrm{C}$. The low rate of failure to rescue in both studies reflects the early recognition and effective management of pancreatic leak, which helped to prevent the development of septic shock and multiple organ dysfunctions. In the current study, none of the patient required postoperative ventilation or renal dialysis. Cardiac complication prevalence was $1 \%$ in the current study, which is similar to what reported by other authors [5].

This report is a single-surgeon series which presents both opportunities and challenges with interpretation. Large multicenter study likely to introduce more variables that would affect the interpretation of modifiable risk factors. Interpretation of multi-surgeon study would be affected significantly by individual surgeon skills. Currently we have no reliable tool to assess individual HPB surgeon technical skills, however changes are coming. Candidates for board-certification in HPB surgery in Japan are required to complete 50 major HPB cases and submit a video of selected surgical procedures for assessment [15-16]. This requirement has significant impact on surgeon skills, from personal experience, and has been recommended in bariatric surgery in the United State [11].

\section{Conclusion}

Further investment in developing meticulous operative technique is likely to achieve reduction in post-PD mortality by reducing the operative and postoperative risk factors.

\section{References}

1. Busnardo AC, DiDio LJ, Tidrick RT, Thomford NR (1983) History of the pancreas. Am J Surg 146(5): 539-550.

2. Swanson RS, Pezzi CM, Mallin K, Loomis AM, Winchester DP (2014) The 90-day mortality after pancreatectomy for cancer is double the 30-day mortality: more than 20,000 resections from the national cancer data base. Ann Surg Oncol 21(13): 4059-4067.

3. Schneider EB, Hyder O, Wolfgang CL, Hirose K, Choti MA, et al. (2012) Patient readmission and mortality after surgery for hepato-pancreatobiliary malignancies. J Am Coll Surg 215(5): 607-615.

4. Nimptsch U, Krautz C, Weber GF, Mansky T, Grützmann R (2016) Nationwide In-hospital Mortality Following Pancreatic Surgery in Germany is Higher than Anticipated. Ann Surg 264(6): 1082-1090.

5. Kimura W, Miyata H, Gotoh M, Hirai I, Kenjo A, et al. (2014) A pancreaticoduodenectomy risk model derived from 8575 cases from a national single-race population (Japanese) using a web-based data entry system: the 30-day and in-hospital mortality rates for pancreaticoduodenectomy. Ann Surg 259(4): 773-780.

6. Suzuki Y, Fujino Y, Ajiki T, Ueda T, Sakai T, et al. (2005) No mortality among 100 consecutive pancreaticoduodenectomies in a middlevolume center. World J Surg 29(11): 1409-1014.

7. Aranha GV, Hodul PJ, Creech S, Jacobs W (2003) Zero mortality after 152 consecutive pancreaticoduodenectomies with pancreaticogastrostomy. J Am Coll Surg 197(2): 223-231.

8. Kimura W (2008) Strategies for the treatment of invasive ductal carcinoma of the pancreas and how to achieve zero mortality for 
pancreaticoduodenectomy. J Hepatobiliary Pancreat Surg 15(3): 270 277.

9. Pugalenthi A, Protic M, Gonen M, Kingham TP, Angelica MI, et al. (2016) Postoperative complications and overall survival after pancreaticoduodenectomy for pancreatic ductal adenocarcinoma. J Surg Oncol 113(2): 188-193.

10. Inoue Y, Saiura A, Yoshioka R, Ono Y, Takahashi M, et al. (2015) Pancreatoduodenectomy With Systematic Mesopancreas Dissection Using a Supracolic Anterior Artery-first Approach. Ann Surg 262(6): 1092-1101.

11. Birkmeyer JD, Finks JF, O’Reilly A, Oerline M, Carlin AM, et al. (2013) Surgical skill and complication rates after bariatric surgery. N Engl J Med 369(15): 1434-1442.

12. Parikh P, Shiloach M, Cohen ME, Bilimoria KY, Ko CY, et al. (2010) ancreatectomy risk calculator: an ACS-NSQIP resource. HPB (Oxford) 12(7): 488-497.
13. Bockhorn M, Uzunoglu FG, Adham M, Imrie C, Milicevic M, et al. (2014) Borderline resectable pancreatic cancer: a consensus statement by the International Study Group of Pancreatic Surgery (ISGPS). Surgery 155(6): 977-988.

14. Hardacre JM (2010) Is there a learning curve for pancreaticoduodenectomy after fellowship training? HPB Surg.

15. Robson AJ, Parks RW (2016) HPB fellowship training: consensus and convergence. HPB (Oxford) 18(5): 397-399.

16. Fujii T, Sugimoto H, Yamada S, Kanda M, Suenaga M, et al. (2014) Modified Blumgart anastomosis for pancreaticojejunostomy: technical improvement in matched historical control study. J Gastrointest Surg 18(6): 1108-1115.

\section{Your next submission with Juniper Publishers} will reach you the below assets

- Quality Editorial service

- Swift Peer Review

- Reprints availability

- E-prints Service

- Manuscript Podcast for convenient understanding

- Global attainment for your research

- Manuscript accessibility in different formats

( Pdf, E-pub, Full Text, Audio)

- Unceasing customer service

Track the below URL for one-step submission https://juniperpublishers.com/online-submission.php 